\title{
Influence of diameter of quartz raw material on the quality of fused
}

\section{quartz product}

\author{
W.H. ZHOU ${ }^{1} \&$ S.G. ZHU ${ }^{1} \&$ X.Z. LIU ${ }^{1}$ \& H.L. ZHANG ${ }^{2}$, Z. ZHAO \\ ${ }^{1}$ School of Energy and Power Engineering, Nanjing University of Science and Technology, China \\ ${ }^{2}$ Lianyungang Research Institute, Nanjing University of Science and Technology, China
}

\begin{abstract}
KEYWORDS: quartz, diameter, fusion, purity
ABSTRACT: The traditional quartz processing industry is characterized by high energy consumption and low purity of product. To save energy and purify the product by a new type of furnace, it is necessary to find the best diameter range of raw material sent in. In order to study the influence of the diameter of quartz raw material on the purity of product, this paper compares 3 kinds of diameter range of quartz which are $0.3-0.45 \mathrm{~mm}, 5-7 \mathrm{~mm}$ and $10-30 \mathrm{~mm}$ by heating and melting the raw material and observing the product. Finally, a conclusion that the highest purity of product will be reached when the diameter is between $5-7 \mathrm{~mm}$ is drawn.
\end{abstract}

\section{INTRODUCTION}

High purity quartz is the main material in the production of monocrystalline silicon, polycrystalline silicon, quartz glass \& optical fiber [1]. It has also been widely used in the industry of VLIC, laser military \& aero or space flight [2]. Thus, high purity quartz is kind of key material that will influence the development of China's industry. However, its high-end processing technology is monopolized by the US and Germany. These countries also restrict the export of high-end quartz products [2].

For a long time, China's quartz processing industry which is represented by Lianyungang area widely uses barrel shaped stainless steel container to contain and heat quartz raw material [3]. This method causes not only lots of energy waste, but also the low level of purity of product [4]. In order to solve this problem, it is necessary to carry out the technological upgrade to purify the product and lower the energy consumption.

The upgraded device includes a crucible and heat resistance material outside the crucible. Due to the fused temperature of quartz is about $1800^{\circ} \mathrm{C}$, the crucible should be able to work strongly and stably enough. Thus the options of crucible material are limited - graphite or TungstenMolybdenum alloy. In the former experiment, we have noticed that quartz expands little when heated, however, alloy or graphite expands much more than quartz. In the cooling process, when the crucible contracts, it will be cracked by the quartz product. This problem has led to a conclusion that the alloy crucible is too expensive to be put into industrial use, therefore, the following experiment will focus on the heating process in graphite crucible.

\section{EXPERIMENT METHODS}

In this paper, an intermediate frequency induction furnace is used to heat the graphite and quartz material. A sketch of furnace is shown in Figure 1.

Because quartz is insulator, induced current will only exist in the graphite crucible, and the heat generated by this current, will be transferred into quartz material mainly through conduction [5]. 
This type of heating method is similar to which really used in the factory. That means the experiment is representative.

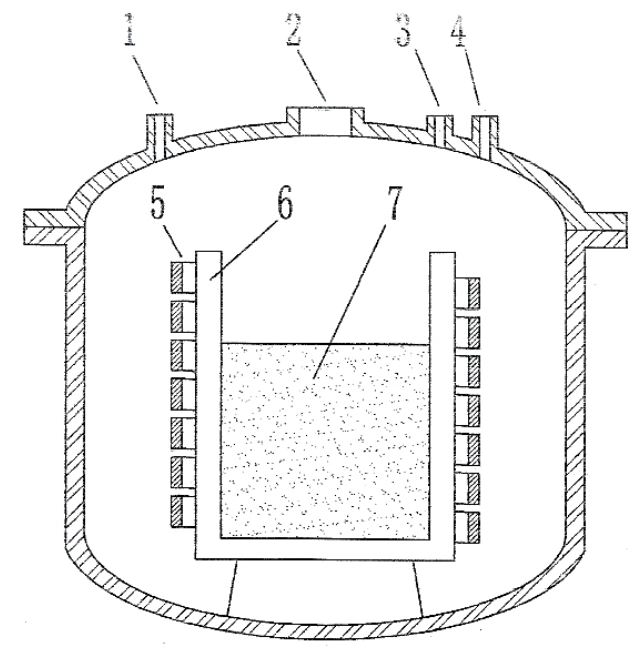

Figure 1 Sketch of intermediate frequency induction furnace

1-port of vacuum pump, 2-radiation pyrometer, 3-port of pressure gauge, 4-port of protective gas, 5-induction heating coil, 6-graphite crucible, 7-quartz material

The processes of experiment are such as these: 1, pump protective gas (Nitrogen or Argon) into the furnace; 2 , set the coil voltage to $200 \mathrm{~V}$ to preheat the crucible; 3 , when the temperature of quartz reaches $1000^{\circ} \mathrm{C}$, raise the coil voltage to $300 \mathrm{~V}$ to accelerate heating process; 4 , when the temperature reaches $1600^{\circ} \mathrm{C}$, raise the voltage again to $350 \mathrm{~V}$ to make up the energy loss and keep the heating rate not too slow; 5 , when temperature reaches $1800^{\circ} \mathrm{C}$ on which quartz begins to fuse, lower down the voltage to $320 \mathrm{~V}$ so that the temperature will go no longer high and keep the quartz continuing to fuse.

This paper compares 3 kinds of diameter range of quartz which are $0.3-0.45 \mathrm{~mm}, 5-7 \mathrm{~mm}$ and $10-30 \mathrm{~mm}$. Figure 2 shows the temperature change in heating process.

According to Figure 2, 45min are required for heating quartz material whose diameter is between $0.3-0.45 \mathrm{~mm}$ from $1000^{\circ} \mathrm{C}$ to $1800^{\circ} \mathrm{C}$ while the diameter of $5-7 \mathrm{~mm}$ and $10-30 \mathrm{~mm}$ require only about $25 \mathrm{~min}$.

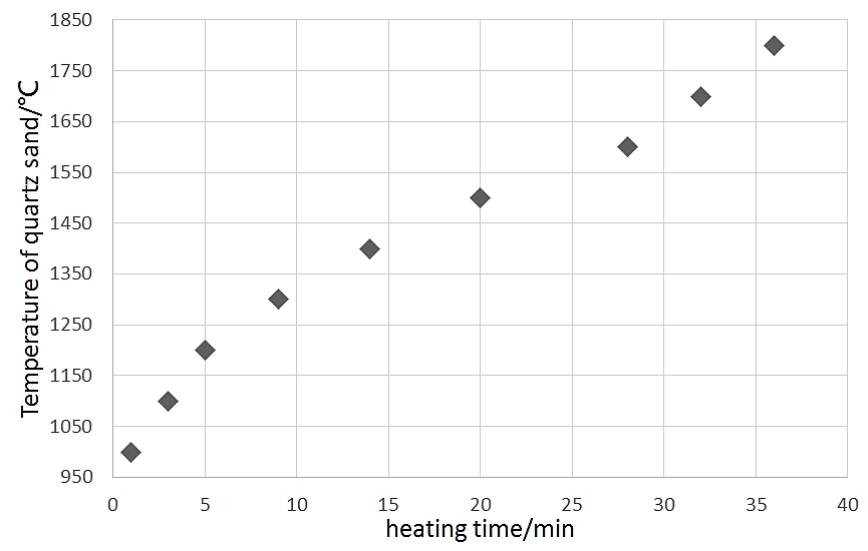

(a) Diameter 0.3-0.45mm 


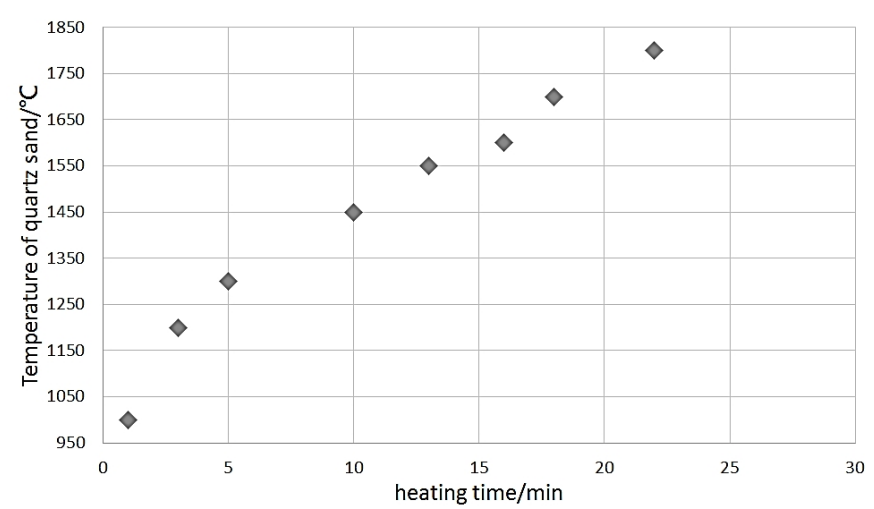

(b) Diameter 5-7 mm

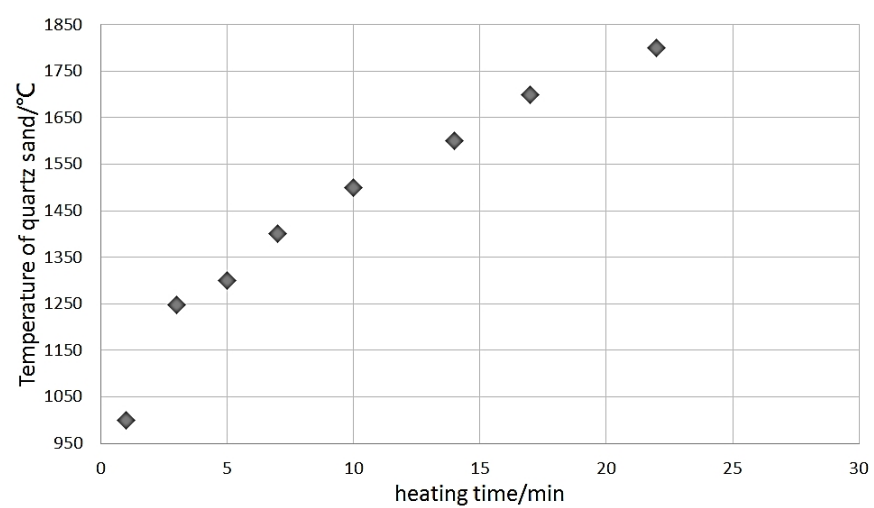

(c) Diameter 10-30mm

Figure 2 Temperature change of quartz $\left(1000-1800^{\circ} \mathrm{C}\right)$

When diameter of quartz material increases, the boundary effect increases significantly. Packing density going down leads to the height of quartz material in crucible increasing. The height of quartz material will influence the area of inner side of crucible exposed to the furnace wall.

Because outside wall is faced with heating coil (high temperature coil covers lots of area of the outside wall so that heat loss from outside wall of crucible is little), the main heat loss is due to radiation of inner exposed to furnace wall. Even though protection methods ( $\mathrm{an} \mathrm{Al}_{2} \mathrm{O}_{3}$ brick acting as radiation shield, its temperature is still much lower than the crucible) has been adopted, heat loss through radiation is not negligible.

The result of this boundary effect is that heat loss of small diameter material is more than the loss of big diameter material. That explains why the heating rate is slower for $0.3-0.45 \mathrm{~mm}$ group and proves that small diameter can transfer heat more quickly by the 2 groups' data indirectly.

\section{PRODUCT ANALYSIS}

The photos of product are shown in Figure 3.

Figure $3 \mathrm{a}$ shows the product of material of diameter range $0.3-0.45 \mathrm{~mm}$, high density of black particles can be observed in the quartz. Black particles are from the graphite crucible. When the diameter of quartz material is small enough, the particles of quartz can flow, and the flow erodes the wall of crucible. Therefore, some graphite particles are peeled off and mixed into the product.

Figure $3 \mathrm{~b}$ shows the product of material of diameter range $5-7 \mathrm{~mm}$, its appearance is uniform which meet the requirements properly.

Figure $3 \mathrm{c}$ shows the product of material of diameter range $10-30 \mathrm{~mm}$, because of the too big diameter, internal of quartz particles doesn't fuse, only the surface has melt and stick together, that 
means more time of temperature preservation is needed. At the same time, some bubbles can be observed. This is because gas in the space between quartz particles is sealed before it escapes. The bubbles also lead to unqualified product.

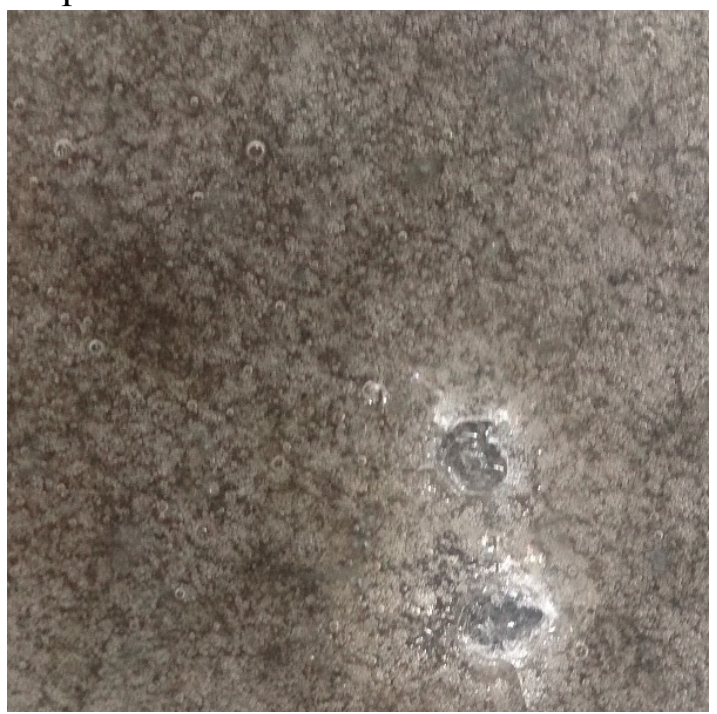

(a)

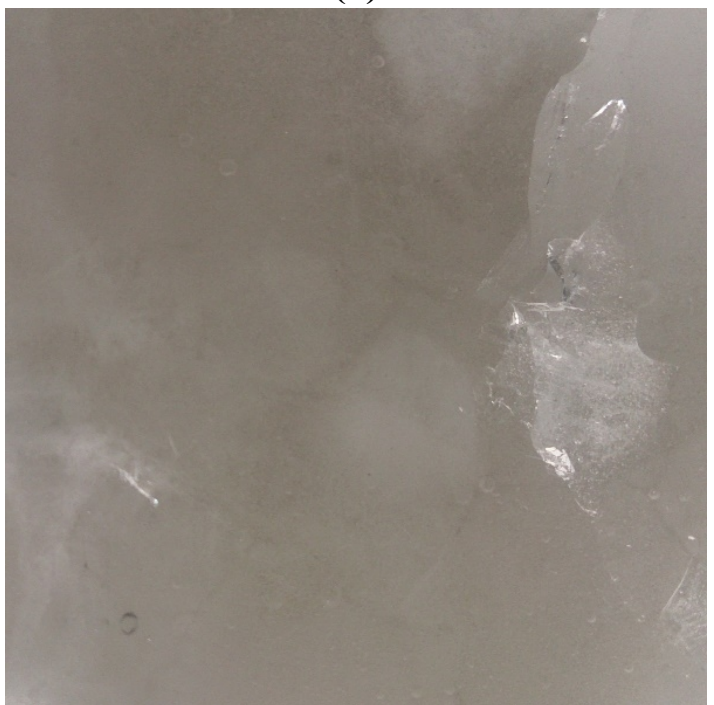

(b)

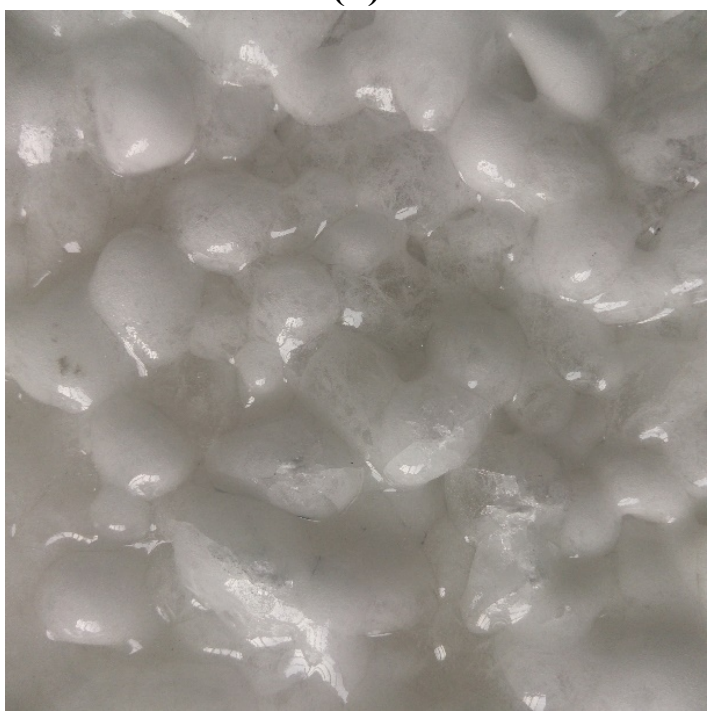

(c)

Figure 3 Product appearance of different material diameter range 


\section{CONCLUSION}

According to the experiment, when the diameter of material is too small $(0.3-0.45 \mathrm{~mm})$, lots of graphite particles will be mixed into the product and that will lead to unqualified product. What's more, small particles also raise the energy consumption of crusher.

When the particles are larger than $10 \mathrm{~mm}$ of diameter, it will be difficult to fuse the particles totally which means more energy consumption of the furnace. And the bubbles in the product are also unwelcomed.

So far, the best diameter range of raw quartz material is $5-7 \mathrm{~mm}$. However, there are still blanks between $0.45-5 \mathrm{~mm}$ and $7-10 \mathrm{~mm}$ which remain to be tested.

\section{ACKNOWLEDGMENT}

This work is supported by the Innovation Fund of University-Industry Cooperation (Prospective joint research project, Lianyungang, Jiangsu Province, No.BY2013047), the Innovation Fund of University-Industry Cooperation (High efficient energy saving project, Lianyungang, Jiangsu Province, No. CXY1327) and the Foundation of State Key Laboratory of Coal Combustion (No. FSKLCC1109).

\section{REFERENCES}

[1] WANG Ling, LI Caixia, WANG Yan, YIN Deqiang. China technologies present of high-purity quartz processing and the development propositions [J]. Journal of Mineralogy and Petrology, 2011, 31(4): 110-114.

[2] SHEN Shifu. The Actuality of Study and Manufacture in Higher Purity Quartz [J]. China Non-Metallic Mining Industry Herald, 2006, (5): 13-16.

[3] CHEN Lei. Potential analysis of fused silica industry energy saving reformation in Donghai county of Jiangsu [J], Power Demand Side Management, 2012, (01): 29-30.

[4] ZHANG Jin, SUN Lili. Fabrication process of quartz glass for optical fiber [A], $4^{\text {th }}$ symposium of high-tech using silicon materials and quartz product market[C], 2006.

[5] I.M Abdulagatov, S.N Emirov, T.A Tsomaeva, Kh.A Gairbekov, S.Ya Askerov, N.A Magomedova. Thermal conductivity of fused quartz and quartz ceramic at high temperatures and high pressures [J]. Journal of Physics and Chemistry of Solids, 2000, 615: 779-787

[6] ZHU Jingwei. Study and design on a new type of quartz melting furnace energy-saving heating system [D]. Nanjing University of Science and Technology, 2015. 